\title{
DENDRITIC CELLS IN PRIMARY SJOGREN'S SYNDROME
}

Wanessa Siqueira Cavalcante (FMUSP, São Paulo, SP, Brasil), Sheyla Batista Bologna Lopes (FOUSP, São Paulo, SP, Brasil), Silvia Vanessa Lourenco (FOUSP, São Paulo, SP, Brasil), Luiz Fernando Ferraz da Silva

(FMUSP, São Paulo, SP, Brasil), Marcello Menta Simonsen Nico (FMUSP, São Paulo, SP, Brasil)

\section{BACKGROUND}

Primary Sjögren's Syndrome is an autoimmune exocrinopathy mainly characterized by an autoimmune epithelitis with lymphomyoepithelial aggression that leads to the destruction of glandular parenchyma, including salivary and lacrimal glands. There is still controversy about the composition of the inflammatory infiltrate in the disease, especially regarding the participation of dendritic cells in the triggering and perpetuation of the chronic inflammation.

\section{MATERIALS AND METHODS}

Thirty (30) samples of labial mucous salivary glands of patients with confirmed diagnosis of primary Sjögren's Syndrome (case group) were gleaned from the archives of the the Dermatopathology Laboratory of the Division of Dermatology, Hospital das Clínicas, Medical School of University of São Paulo - HCFMUSP. The histological aspects of all specimens of salivary glands included in the study were analyzed by two pathologists to classify the degree of alteration of the glandular parenchyma. Immunohistochemistry was performed to investigate the quality of the inflammatory infiltrate present in the specimens through the identification of proteins CD1a, Langerin, CD21, CD123, CD68, CD3, CD4, CD8, CD20 and BCL6. Subsequently morphometric analyses were performed by using the Image-Pro Plus technology.

\section{RESULTS}

In the cases classified with moderate and intense lymphomyoepithelial infiltrate there was also the presence of plasmacytoid dendritic cells CD123 positive and predominance of lymphocytes CD4 and CD20 positive.

\section{CONCLUSION}

This study concluded that plasmacytoid dendritic cells were present in salivary glands samples from patients with primary Sjögren's Syndrome and are likely to orchestrate the perpetual inflammatory process in the disease. 